\title{
Przedstawienie wybranych rozwiązań technicznych i technologicznych stosowanych w urządzeniach do badań przesiewowych stuchu u dzieci w wieku szkolnym
}

\section{Introduction of selected technical and technological solutions implemented in devices designed for hearing screening in school-age children}

\section{Krzysztof Tarczyński, Anna Piotrowska}

Instytut Fizjologii i Patologii Słuchu, Światowe Centrum Słuchu, Zakład Epidemiologii i Badań Przesiewowych, Warszawa/Kajetany

Adres autora: Krzysztof Tarczyński, Światowe Centrum Słuchu, Zakład Epidemiologii i Badań Przesiewowych, Kajetany, ul. Mokra 17, 05-830 Nadarzyn, e-mail: k.tarczynski@ifps.org.pl

\section{Streszczenie}

Badania audiometryczne są często wykorzystywane podczas masowych programów badań przesiewowych słuchu u dzieci w wieku szkolnym. Wykonuje się je za pomocą urządzeń zwanych audiometrami, które ze względu na dokładność pomiaru można podzielić na kliniczne, diagnostyczne i skriningowe.

Celem niniejszej pracy jest przedstawienie rozwiązań technicznych i technologicznych zastosowanych w 14 wybranych urządzeniach do audiometrycznych badań przesiewowych słuchu u dzieci w wieku szkolnym. Prezentacja została dokonana pod kątem przydatności tych rozwiązań w realizacji programów badań masowych.

Słowa kluczowe: badania przesiewowe słuchu • audiometr • dzieci szkolne

Abstract

Audiometric measurements are often used in hearing screening programs in school children. Tests are performed using devices called audiometers, which due to measurement accuracy can be divided as clinical, diagnostic or screening devices.

The aim of this study was to evaluate technical and technological solutions used in 14 selected devices for audiometric screening in school-age children from the point of view of their usefulness in mass screening programs.

Key words: hearing screening • audiometer • school children

\section{Wprowadzenie}

W badaniach przesiewowych słuchu u dzieci w wieku szkolnym można wykorzystywać metody obiektywne i/lub audiometryczne. Metody audiometryczne, preferowane $\mathrm{w}$ tej grupie wiekowej, zakładają aktywne uczestniczenie dziecka w badaniu [1,2]. Badania audiometryczne dostarczają informacji o sprawności słuchu dziecka w zakresie niskich, średnich i wysokich tonów. Badania te są nieinwazyjne, bezbolesne i nieuciążliwe dla dziecka. Ze względu na dokładność pomiaru audiometry można podzielić na kliniczne, diagnostyczne i skriningowe. Testy audiometryczne, pod względem techniki wykonania, mogą być manualne, półautomatyczne oraz automatyczne.
Podczas testu audiometrycznego manualnego osoba wykonująca badanie samodzielnie steruje podawaniem dźwię$\mathrm{ku}$, jego natężeniem oraz częstotliwością, a następnie wyznacza próg słyszenia. Test automatyczny wymaga jedynie uruchomienia, cały cykl badania odbywa się samoczynnie. Przy teście półautomatycznym badający przed uruchomieniem testu może ustawić parametry badania, takie jak poziom natężenia dźwięku lub skok tłumika, po czym badanie przebiega tak jak w przypadku testu automatycznego.

Celem niniejszej pracy jest prezentacja rozwiązań technicznych i technologicznych stosowanych w wybranych urządzeniach do audiometrycznych badań przesiewowych słuchu u dzieci w wieku szkolnym, dokonana pod kątem 
przydatności tych rozwiązań w realizacji programów badań masowych.

\section{Materiał i metoda}

Ocenie poddano urządzenia, które są aktualnie produkowane i dostępne na rynku, a ilość informacji podanych przez producentów w broszurach i instrukcjach obsługi pozwalała na taką ocenę. Wybrano 14 audiometrów różnych producentów. Do oceny wykorzystano materiały dostępne na stronie internetowej wirtualnej wystawy urządzeń medycznych [3], a także informacje umieszczone w broszurach i instrukcjach obsługi urządzeń na stronach internetowych następujących producentów lub dystrybutorów: Distrimed [4] - dystrybutor audiometru Amplivox 170, Eymasa [5] - producent audiometru Redus 85, Oscar Instrument [6] - dystrybutor audiometru SA202, GM-Instruments [7] - producent audiometru Asra Audiometer, Grason Stadler [8] - producent audiometru GSI 18, Intelligent Hearing Systems [9] - producent audiometru Smart Audiometer, Otometrics [10] - producent audiometru Madsen Micromate 304, Maico [11] - producent audiometrów MA 1 i MA 25, Inmedico [12] - producent audiometru Oscilla USB 330, Otovation [13] - producent audiometru Amplitude T3, Videomed [14] - producent audiometru nSmart, Medincus [15] - producent audiometru Platforma Badań Zmysłów, Piston [16] - producent audiometru PDD-401. Kategoryzacji oraz oceny przydatności audiometrów skriningowych dokonano $\mathrm{z}$ wykorzystaniem następujących kryteriów:

- Kategoria I: rodzaj testów (manualny, półautomatyczny, automatyczny), zakres badanych częstotliwości, zakres intensywności bodźca.

- Kategoria II: mobilność (wymiary, waga, zasilanie, drukowanie wyników).

- Kategoria III: możliwości zapisu i przechowywania wyników w zewnętrznej bazie danych.

\section{Wyniki}

\section{Kategoria I}

Urządzenia umożliwiające wykonanie testu audiometrycznego manualnego

Wykonanie jedynie manualnego testu audiometrycznego umożliwiają urządzenia: MA 1 wyprodukowane przez Maico, GSI 18 firmy Grason-Stadler, Amplitude T3 wyprodukowany przez Otovation oraz audiometr nSmart produkcji Videomed.

Urządzenie GSI 18 umożliwia badanie w zakresie częstotliwości $0,125-8 \mathrm{kHz}, \mathrm{z}$ możliwością badania wszystkich częstotliwości półoktawowych od 0,5 kHz, z dokładnością $\pm 2 \%$. Zakres natężeń sygnału audiometru GSI 18 zróżnicowany jest w zależności od częstotliwości i zawiera się w przedziale od -10 do $50 \mathrm{~dB} \mathrm{HL}$ dla $125 \mathrm{~Hz}$, od -10 do $90 \mathrm{~dB}$ HL dla przedziału $0,5-4 \mathrm{kHz}$, od -10 do $85 \mathrm{~dB} \mathrm{HL}$ dla $6 \mathrm{kHz}$ oraz od -10 do $70 \mathrm{~dB}$ HL dla 0,25 i $8 \mathrm{kHz}$. Dokładność intensywności wynosi $\pm 3 \mathrm{~dB}$ HL dla częstotliwości od 0,125 do $4 \mathrm{kHz}$ oraz $\pm 5 \mathrm{~dB}$ HL dla częstotliwości 6 i $8 \mathrm{kHz}$. GSI18 wyposażony jest w słuchawki typu DD 45. Badanie może odbywać się z wykorzystaniem sygnału ciągłego, pulsacyjnego lub modulowanego.
Podobny zakres badanych częstotliwości oraz rodzaje generowanych sygnałów posiada audiometr skriningowy nSmart. Urządzenie to ma jednak większy zakres intensywności, tj. od -10 do 130 dB HL. Standardowo wyposażony jest $\mathrm{w}$ słuchawki PD-81 z osłonami przeciwhałasowymi. Audiometr MA 1 pozwala na wykonanie testu manualnego tylko dla czterech częstotliwości: $0,5,1,2$, $4 \mathrm{kHz}$ (zniekształcenie na poziomie poniżej 3\%) w przedziale intensywności od 15 do $50 \mathrm{~dB}$ HL, z dokładnością do \pm 4 dB. Podobnie jak audiometr GSI18, tak i urządzenie MA 1 posiada w wyposażeniu słuchawki typu DD 45 , ma jednak możliwość generacji jedynie czystego tonu ciągłego.

Audiometr Amplitude T3 wyróżnia w tej grupie urządzeń możliwość wykonywania pomiaru progów słyszenia zarówno dla przewodnictwa powietrznego, jak i dla przewodnictwa kostnego, z maskowaniem w zakresie częstotliwości od 0,125 do $8 \mathrm{KHz}$ dla przewodnictwa powietrznego oraz $0,25-6 \mathrm{kHz}$ dla przewodnictwa kostnego, w przedziale intensywności od - 10 do $110 \mathrm{~dB}$ HL dla przewodnictwa powietrznego oraz od -10 do $60 \mathrm{~dB}$ HL dla przewodnictwa kostnego. Urządzenie współpracuje ze słuchawkami TDH 39, EAR 5A, HDA 200 dla przewodnictwa powietrznego oraz B-71 dla przewodnictwa kostnego. Do badań może być wykorzystywany ton ciągły lub pulsacyjny.

\section{Urządzenia umożliwiające wykonanie testu audio- metrycznego manualnego i automatycznego}

Wykonanie testu audiometrycznego manualnego i automatycznego umożliwiają urządzenia Smart Audiometer, Amplivox 170, Redus-85 produkcji Eymasa, SA202 produkcji Entomed, Madsen Micromate 304 produkcji Otometrics, MA-25 produkcji Maicon, PDD-401 produkcji PISTON, audiometr Oscilla USB 330 produkcji Inmedico oraz Platforma Badań Zmysłów wyprodukowana przez firmę Medincus.

Smart Audiometer charakteryzuje się największym, spośród wszystkich omawianych urządzeń, zakresem częstotliwości, od 0,25 do $16 \mathrm{kHz}$, z przedziałem intensywności od -10 do 100 dB HL. Skok tłumika audiometru można ustawić na poziomie 1, 2, 5 lub $10 \mathrm{~dB}$. Ten model audiometru generuje czysty ton ciągły lub przerywany.

Zakres częstotliwości audiometru Amplivox 170 wynosi od 0,25 do $8 \mathrm{kHz}$ z trzema częstotliwościami półoktawowymi 1,5, 3 i $6 \mathrm{kHz}$. Automatyczna wersja testu umożliwia włączenie do badania lub wyłączenie $\mathrm{z}$ badania częstotliwości $0,25 \mathrm{kHz}$ i/lub $8 \mathrm{kHz}$. Dokładność wartości częstotliwości wynosi poniżej 1\%, a zniekształcenie poniżej $2 \%$. Zakres intensywności sygnału jest porównywalny do audiometru Smart i wynosi od -10 do 100 dB HL, z dokładnością $\pm 3 \mathrm{~dB}$. Możliwa jest tylko jedna wartość skoku tłumika $-5 \mathrm{~dB}$. Audiometr generuje czysty ton podawany przez słuchawki TDH 39.

Model Redus-85 produkcji Eymasa umożliwia badanie słuchu w podobnym jak Amplivox 170 zakresie częstotliwości, ale posiada możliwość badania jedynie dwóch częstotliwości półoktawowych - 3 i $6 \mathrm{kHz}$. Także zakres intensywności oraz skok tłumika są identyczne. Redus-85 wykorzystuje czysty ton ciągły lub pulsacyjny. 
Rozszerzony - od 0,125 kHz do $8 \mathrm{kHz}$ zakres badanych częstotliwości - charakteryzuje audiometry MADSEN Micromate 304, SA202, MA-25, OSCILLA USB 330 oraz Platformę Badań Zmysłów. Różnice między tymi urządzeniami wynikają z możliwości pomiarów na różnych częstotliwościach półoktawowych oraz różnych zakresów intensywności sygnału.

Madsen Micromate 304 posiada trzy częstotliwości półoktawowe - 1,5, 3 i $6 \mathrm{kHz}$ oraz zakres intensywności od -10 do $90 \mathrm{~dB}$ HL (dokładność $\pm 3 \mathrm{~dB}$ HL). Ten rodzaj audiometru wyposażony jest w słuchawki typu TDH 39 i generuje czysty ton.

Model SA202, podobnie jak MA-25 oraz PDD-401, ma możliwość wykonywania pomiaru na wszystkich częstotliwościach półoktawowych z zakresu 0,5-8 kHz. SA202 charakteryzuje się dokładnością natężenia sygnału na poziomie $\pm 1 \%$. Zakres intensywności audiometru zawiera się w przedziale od -20 do $120 \mathrm{~dB}$ HL dla SA202 oraz od -10 do $100 \mathrm{~dB}$ HL dla MA-25 i PDD-401. Poprzez słuchawki TDH 39, DD 45, HDA 200 lub EAR 5A urządzenie SA202 generuje czysty ton pojedynczy, ciągły lub pulsacyjny. Model MA-25 generuje czysty ton pulsacyjny i modulowany, podawany przez słuchawki DD 45 . Dodatkowo w modelu tym istnieje możliwość wyboru wartości skoku tłumika 1 lub 5 dB HL. Audiometr PDD-401 ma w wyposażeniu słuchawki TDH 39, generuje czysty ton ciągły, pulsacyjny i przerywany.

Możliwość badania wszystkich częstotliwości półoktawowych powyżej $0,5 \mathrm{kHz}$ charakteryzuje także model MA-25. Zakres jego intensywności zawiera się w przedziale od -10 do $100 \mathrm{~dB}$ HL. Skok tłumika można wybrać na poziomie 1 lub $5 \mathrm{~dB}$ HL. Urządzenie generuje czysty ton pulsacyjny i modulowany, podawany przez słuchawki DD 45 . Taki sam zakres intensywności ma też model PDD-401, w którego wyposażeniu znajdują się słuchawki TDH 39, a rodzaj sygnału to czysty ton ciągły, pulsacyjny i przerywany.

Audiometr Oscilla USB 330 pozwala na przeprowadzenie testu manualnego, 2 automatycznych testów skriningowych $20 \mathrm{~dB}$ oraz automatycznego testu progowego metodą Hughson\&Westlake. Urządzenie to umożliwia badanie na wszystkich częstotliwościach półoktawowych z zakresu $0,5-8 \mathrm{kHz}$, a zakres intensywności sygnału oraz rodzaj słuchawek jest taki sam, jak w modelu PDD-401. Urządzenie generuje sygnał ciągły, pulsacyjny lub modulowany.

Platforma Badań Zmysłów posiada trzy częstotliwości półoktawowe 1,5, 3 i $6 \mathrm{kHz}$. Zakres intensywności sygnału w przedziale $0,125-8 \mathrm{kHz}$ wynosi od 0 do $80 \mathrm{~dB}$ HL. Prezentacja tonów odbywa się w trybie impulsowym poprzez słuchawki HDA 200. Oprócz testów audiometrycznych urządzenie to pozwala również na wykonanie innych badań, takich jak test słyszenia rozdzielnousznego (ang. dichotic digit test, DDT), test wykrywania przerw w szumie (ang. gap detection test, GDT), test tonalny, badania wzroku i mowy. Za pomocą PBZ można również przeprowadzić dowolną ankietę utworzoną wcześniej w centralnej bazie danych.
Urządzenia umożliwiajace wykonanie testu audiometrycznego manualnego, półautomatycznego i automatycznego

Wykonanie testu audiometrycznego manualnego, półautomatycznego i automatycznego umożliwia jedynie model Asra Audiometer. Urządzenie to charakteryzuje się zakresem częstotliwości od 0,125 do $12 \mathrm{kHz}$, włączając wszystkie częstotliwości półoktawowe od $0,5 \mathrm{kHz}$. Generowany sygnał to impulsy pojedyncze lub wielokrotne o natężeniu od -20 do 120 dB HL. Wysoka dokładność, zarówno częstotliwości $( \pm 0,1 \%)$, jak i natężenia dźwięku (do 1 dB HL), wyróżnia ten audiometr spośród wszystkich prezentowanych.

\section{Kategoria II}

Jedną z ważniejszych właściwości urządzeń do badań przesiewowych słuchu jest ich mobilność, tzn. możliwość wykonywania badań w terenie, w różnych warunkach. Istotne znaczenie mają więc parametry takie jak wymiary (długość $\times$ szerokość $\times$ wysokość), waga urządzenia, typ zasilania czy też możliwość drukowania wyników badań.

Jako moduły podłączane do komputera funkcjonują modele nSmart, Amplitude T3, PDD-401, Oscilla USB 330 oraz Smart Audiometer. Posiadają one możliwość wydruku wyników badań na dowolnej drukarce obsługiwanej przez system Windows, podłączonej do komputera. Najlżejszym $\mathrm{z}$ nich jest audiometr nSmart, o wymiarach $12 \times 6,5 \times 2,8$ $\mathrm{cm}$, który bez przetworników waży $100 \mathrm{~g}$. Audiometr ten łączy się z komputerem przez port USB 2.0. Tak też jest zasilany, podobnie jak model PDD-401, który waży $200 \mathrm{~g}$ i ma wymiary $15 \times 8,2 \times 4,5 \mathrm{~cm}$. Amplitude T3 waży $160 \mathrm{~g}$. Łączy się z komputerem za pomocą sieci bluetooth, której zasięg wynosi 9 metrów. Zasilanie umożliwia zewnętrzny zasilacz sieciowy lub 2 akumulatory AA. Oscilla USB 330 jest urządzeniem nieco cięższym - waży $500 \mathrm{~g}$.

Jako urządzenia samodzielne działają audiometry Amplivox 170, MA 1, MA 25, GSI 18, Madsen Micromate 304, SA202, Asra Audiometer, Redus-85 oraz Platforma Badań Zmysłów. Poniżej jednego kilograma ważą audiometry MA 1 (450 g) oraz Amplivox 170 (700 g), powyżej kilograma urządzenia: MA 25 (1 kg bez baterii i słuchawek), GSI 18 (1,1 kg), Madsen Micromate $304(1,28 \mathrm{~kg} \mathrm{z}$ bateriami), Platforma Badań Zmysłów (1,3 kg), SA202 (1,5 $\mathrm{kg})$, Asra Audiometer (2 kg) oraz najcięższy z opisywanych Redus-85 (4,5 kg). Audiometry GSI 18, MA 1, MA 25 i Madsen Micromate 304 nie mają możliwości współpracy z komputerem oraz wydruku wyników badań. GSI 18, MA 25 i Madsen Micromate 304 są wyposażone w karty $\mathrm{z}$ siatką audiogramu do ręcznego wypełniania.

Audiometr GSI 18 o wymiarach $32 \times 22,4 \times 8,1 \mathrm{~cm}$ jest zasilany przez zewnętrzny zasilacz sieciowy lub 5 baterii alkalicznych AA, pozwalających na 10 godzin pracy. Zasilanie z dwóch źródeł posiada także Madsen Micromate 304, (wymiary: $30 \times 21 \times 6 \mathrm{~cm}$ ) oraz MA 25 (wymiary: $22,5 \times 18 \times 5,5$ $\mathrm{cm}$ ). MA 1 zasilany jest $\mathrm{z} 2$ baterii alkalicznych AA, a jego wymiary to $15,24 \times 6,35 \times 2,22 \mathrm{~cm}$.

Audiometr Amplivox 170 o wymiarach $27 \times 17,5 \times 6,8 \mathrm{~cm}$ zasilany jest podobnie jak GSI 18, Madsen Micromate 304 
oraz MA 25 z dwóch źródeł: zasilacza oraz baterii alkalicznych, pozwalających na 6-8 godzin pracy. Urządzenie opcjonalnie wyposażone jest w przenośną drukarkę termiczną. Redus-85, SA 202 oraz Asra Audiometer zasilane są jedynie poprzez zasilacz sieciowy. SA 202 (wymiary: $37,6 \times 26,4 \times 7,3 \mathrm{~cm}$ ) i Asra Audiometer (wymiary: $27 \times 28 \times 6 \mathrm{~cm}$ ) umożliwiają wydruk wyników badań na dowolnej drukarce zewnętrznej, natomiast Redus-85 (wymiary: $43 \times 22 \times 8,5 \mathrm{~cm}$ ) opcjonalnie wyposażony jest $\mathrm{w}$ drukarkę termiczną.

Platforma Badań Zmysłów, o wymiarach $26 \times 18 \times 4 \mathrm{~cm}$, pozwala na wydruk wyników na dowolnej drukarce obsługiwanej przez system Windows. Zasilanie odbywa się poprzez zewnętrzny zasilacz sieciowy lub wewnętrzną baterię notebooka.

\section{Kategoria III}

Bardzo ważną cechą audiometrów skriningowych jest możliwość zapisu i przechowywania wyników badań w zewnętrznej bazie danych. Możliwością taką charakteryzują się wszystkie urządzenia, które współpracują z komputerem. Są to zarówno urządzenia samodzielne, jak i pracujące jako moduł komputera oraz te zbudowane na bazie komputera.

Cztery z prezentowanych w pracy urządzeń nie pozwalają na zapis i przechowywanie wyników badań w zewnętrznej bazie danych. Są to GSI 18, Madsen Micromate 304, MA 1 i MA 25. Wszystkie są urządzeniami samodzielnymi, nieposiadającymi pamięci wewnętrznej i zdolności do współpracy z komputerem.

Amplivox 170, Redus-85, SA202 i Asra Audiometer są urządzeniami samodzielnymi z możliwością podłączenia do komputera za pomocą portu USB. Amplivox 170 posiada dodatkowo pamięć wewnętrzną mieszczącą 12 kompletnych testów, opcjonalnie wyposażony jest w płytę $\mathrm{z}$ oprogramowaniem audiometrycznym Audibase. Pamięć wewnętrzna audiometru SA202 pozwala na zapisanie 50 kompletnych testów. Urządzenie posiada oprogramowanie audiometryczne Audimax II+ jako opcję wyposażenia. Redus 85 nie ma własnej pamięci wewnętrznej, wyniki badań mogą być zapisane na dysku komputera za pomocą opcjonalnego oprogramowania audiometrycznego Redusoft. Asra Audiometer charakteryzuje się bardzo dużą pojemnością pamięci wewnętrznej, posiada własny dysk twardy i oprogramowanie.

Platforma Badań Zmysłów to urządzenie zbudowane na bazie notebooka MSI z oprogramowaniem PBZ. Wyniki badań przesyłane są do centralnej bazy danych za pomocą sieci Internet.

Pozostałe pięć audiometrów: Smart Audiometer, Oscilla USB 330, Amplitude T3, nSmart oraz POD-401 to urządzenia pracujące jako moduł komputera, które łączą się z komputerem przez port USB, za wyjątkiem audiometru Amplitude T3, który łączy się przez sieć bluetooth. Smart Audiometer wyposażony jest w oprogramowanie umożliwiające zapis i eksport wyników badań do zewnętrznej bazy danych. Oscilla USB 330 posiada oprogramowanie $\mathrm{z}$ bazą danych, generatorem raportów i przyjaznym interfejsem użytkownika. Audiometr nSmart wyposażony jest w oprogramowanie Effetha Audio umożliwiające zapis wyników w zewnętrznej bazie danych.

\section{Dyskusja}

Podczas prowadzenia masowych badań przesiewowych słuchu $\mathrm{w}$ terenie jednym $\mathrm{z}$ ważniejszych parametrów urządzenia wykorzystywanego do badań jest mobilność, a w szczególności niewielkie wymiary i waga, oraz zasilanie z co najmniej dwóch źródeł. Spośród przedstawionych w pracy audiometrów najlepsze parametry charakteryzujące wymiary i wagę posiadają: Smart Audiometer, MA 1, Oscilla USB 330, Apmplitude T3, nSmart oraz SA 202. Wymienione urządzenia, $\mathrm{z}$ wyjątkiem MA 1, mają również co najmniej dwa niezależne źródła zasilania. Dla celów statystycznych oraz raportowania wyników prowadzonych badań pożądana jest także możliwość zapisu i przechowywania wyników badań w zewnętrznej bazie danych, co umożliwiają Smart Audiometer, Oscilla USB 330, nSmart oraz Platforma Badań Zmysłów. Użytkownik powinien również zwrócić uwagę na wybór dostępnych testów, zakres częstotliwości i natężenia sygnału oraz dokładność pomiarową urządzenia. Spośród opisanych w pracy urządzeń najszerszy zakres testów posiada Platforma Badań Zmysłów. Audiometr Aplitude T3 jest jedynym spośród opisywanych, który pozwala na przeprowadzenie testu audiometrycznego również dla przewodnictwa kostnego. Niemal wszystkie opisywane urządzenia, z wyjątkiem najprostszego MA 1, posiadają szeroki zakres badanych częstotliwości, z możliwością badania częstotliwości półoktawowych. Pod względem dokładności zarówno częstotliwości, jak i natężenia dźwięku wyróżnia się zdecydowanie Asra Audiometer. Badanie w największym zakresie natężenia dźwięku umożliwiają: Asra Audiometer, Oscilla USB 330, Amplitude T3, nSmart i PDD-401.

\section{Podsumowanie}

Zróżnicowanie pod względem wybranych parametrów audiometrów skriningowych pozwala na wybór odpowiedniego urządzenia do badań, w zależności od potrzeb określonych przez realizatora programu przesiewowych badań słuchu.

Publikacja powstała $w$ związku $z$ realizacja projektu pn. „Zintegrowany system narzędzi do diagnostyki i telerehabilitacji schorzeń narządów zmysłów (słuchu, wzroku, mowy, równowagi, smaku, powonienia)" INNOSENSE, wspólfinansowanego przez Narodowe Centrum Badań i Rozwoju w ramach Programu STRATEGMED. 


\section{Piśmiennictwo:}

1. Śliwa L, Hatzopoulos S, Kochanek K, Piłka A, Senderski A, Skarżyński PH. A comparison of audiometric and objective methods in hearing screening of school children. A preliminary study. Int J Pediatr Otorhinolaryngol, 2011; 75(4): 483-88.

2. Skarżyński H, Piotrowska A. Screening for pre-school and school-age hearing problems: European Consensus Statement. Int J Pediatr Otorhinolaryngol, 2012; 76(1): 120-21.

3. www.medicalexpo.com.

4. www.distrimed.com.

5. www.eymasa.com.

6. www.oscarinstrument.se.
7. www.gm-instruments.com.

8. www.grason-stadler.com.

9. www.ihsys.com.

10. www.otometrics.com.

11. www.maico-diagnostic.com.

12. www.inmedico.com.

13. www.otovation.com.

14. www.videomed.eu.

15. www.csim.pl.

16. www.pistonmedical.com. 